\title{
CORRESPONDENCE
}

\section{Soviet Scientists}

SIR,-This is the typescript of a message received by telephone from Professor Levich on November 26, 1972.

Open Letter to Academician Keldysh, President of the USSR Academy of Sciences:

Since 1724, when the Russian Academy of Sciences was founded, there has hardly been a situation like the present one. For nearly a year, the President of the Academy has been declining to see, or even to reply to the letters of, a group of scientists including professors and a corresponding member of the Academy. Therefore we are compelled to address you in this open letter.

We believe that as the official head of Soviet science you must, and that as a member of the Central Committee of the Communist Party you can, intervene actively in the tragic case of scientists who wish to repatriate to Israel and who are forcibly detained in this country under the pretext of "government interests" and "secrecy considerations". You will certainly agree that the progress of science cannot be achieved without freedom of conscience and freedom of moral convictions for scientists. The singling out of scientists and specialists into a discriminated category as compared to others cannot but arouse the concern and indignation of the world scientific community.

It is your duty to explain to the authorities that the forcible detention of scientists, and at the same time their persecution, is doing irreparable harm to the prestige of that body of scientists of which you are the leader. You know that, quite apart from written agreements and the formal fulfilment of exchange plans, spiritual cooperation among scientists of different countries is a significant reality; and it is this kind of cooperation which is being damaged, because the world scientific community cannot and will not remain indifferent to the persecution of its members. This is what actually does real harm to the government's interests.

As to the so-called secrecy, to begin with you will probably agree that, under existing Soviet conditions, those who are at present really aware of any important secrets will not apply for exit visas. As a scientist, you understand perfectly well that scientific progress is so rapid that scientific and technological secrets become obsolete within some two or three years.
Meanwhile, just as you, on your visit to the United States of America, were proclaiming a humane and reasonable approach to the problem of repatriation of Jewish scientists, the deputy Minister of the Interior, General Shumelin, publicly declared the time of detention of scientists on the grounds of secrecy to be up to twenty years. We ask you, Mr President: who determines the fate of scientists in the long run? You, the head of Soviet science or generals of the Ministry of Internal Affairs?

The agreement which has been recently concluded between the USSR and the USA has clearly shown that the exchange of scientific and technological information is much more important than the keeping of secrecy, even in such new and important areas as the cosmos. We wonder whether in this situation it is admissible to treat seriously the poor remnants of the allegedly secret but long obsolete information known to some of us.

The convincing proof that the socalled secrecy considerations are worthless is the fact that several scientists and specialists obtained exit visas this October who, only a few weeks before, were refused visas on "secrecy considerations". Explaining the situation more frankly, General Verein, the chief of OVIR of the USSR, who is responsible for questions concerning exit permits, on November 20 officially confirmed that it is preferable to let a scientist rot in this country than to enable him to work somewhere else ; our worst predictions have obviously come true. We have already come to be considered as the inalienable property of the state.

$\mathrm{Mr}$ President, we suggest that you should publicly condemn such disgraceful treatment of those who dare to fight for their natural human rights ; otherwise you inevitably become an associate of those who promote the above ideas. We suggest that you should secure the legally established procedure of repatriation for scientists to Israel, this procedure being public and based on reason and laws. We wonder, Mr President, whether you yourself will perceive it as your urgent moral duty so to do.

Signed by: Benjamin Levich, corresponding member of the Academy of Sciences of the USSR; Professor Alexander Lerner; Professor Vladimir Mash ; Professor Jevsei Ratner ; Professor Alexander Voronel.

Yours faithfully, D. B. Spalding

Imperial College, London SW7 $2 B X$

\section{Cancer Research}

SIR,- May I be allowed to correct two statements in the article in your issue of December 1 headed "Lord Zuckerman Defends His Position", in which you refer to remarks I am quoted as having made at a meeting of the British Association for Cancer Research.

The first is in the opening sentence, which says that I have advocated a "policy of parsimony in cancer research".

I have advocated no such policy, either for cancer research or for any other form of research. If such a policy has been mooted, it must have been in your original comment on the report I prepared for the Prime Minister (Nature, 240, $4 ; 1972$ ), and to which you now refer again. As opposed to what appears in Nature, what I wrote is that a sudden increase in funds for cancer research could not be effectively used, whereas " a steady and substantial increase over the years would probably yield valuable results".

Your second error is the statement that I "launched a counter attack on the scientific community", which I accused of "narrow mindedness". I have levelled no such accusation, and since I have not been attacked, there was no need, even if I had wished to do so, for me to launch a counter attack. What I pointed out at the meeting was that applications for research grants are inevitably judged by assessors whose personal experience of what constitutes fruitful research necessarily influences, some would say prejudices, their judgment. There is, however, no sensible alternative to this normal procedure for dealing with applications for funds, and equally there is nothing new in my observation. It has been made time and time again, not only in comment on what the Americans call "peer review", but also on the review process whereby a scientific paper is judged worthy of publication. As those who are familiar with the history of science know, there have unfortunately been instances of reports of major scientific advances whose publication has been delayed for years, even decades, by what we would today call the editorial process. Instances can even be found in the cancer field. What $I$ appealed for at the meeting at the Association for Cancer Research is that this fact be borne in mind when support is sought for what may seem, in the frame- 